\author{
盟 \\ BAHIANA

\section{Relato de experiência: construção de um modelo para ensino de ausculta cardíaca em bases semiológicas}

\title{
Construction of a cardiac auscultation educational model for semiology"s bases: experience report
}

\author{
Tiago Alves dos Santos' , Luca Moreira Baggio Vieira², Marília Menezes Gusmão³, \\ Marta Silva Menezes ${ }^{4}$, Matheus de Sena Rocha ${ }^{5}$, Rebecca Anjos Guimarães Silva ${ }^{6}$
}

'Autor para correspondência. Escola Bahiana de Medicina e Saúde Pública. Salvador, Bahia, Brasil. ORCID: 0000-0002-2163-0242. tiagosantos16.2@bahiana.edu.br

2Escola Bahiana de Medicina e Saúde Pública. Salvador, Bahia, Brasil. ORCID: 0000-0001-5140-5620. tiagosantos16.2@bahiana.edu.br ${ }^{3}$ Escola Bahiana de Medicina e Saúde Pública. Salvador, Bahia, Brasil. ORCID: 0000-0002-7907-2503. mariliagusmao.pos@bahiana.edu.br ${ }^{4}$ Escola Bahiana de Medicina e Saúde Pública. Salvador, Bahia, Brasil. ORCID: 0000-0001-7713-518X. martamenezes@bahiana.edu.br ${ }^{5}$ Escola Bahiana de Medicina e Saúde Pública. Salvador, Bahia, Brasil. ORCID: 0000-0002-4062-8121. matheusrocha16.2@bahiana.edu.br ${ }^{6}$ Escola Bahiana de Medicina e Saúde Pública. Salvador, Bahia, Brasil. ORCID: 0000-0002-6014-0529. rebeccasilva17.2@bahiana.edu.br

\section{Contexto da situação}

O eixo de abordagem do componente curricular Bases da Semiologia da Escola Bahiana de Medicina e Saúde Pública (EBMSP) propõe ações de treinamento de forma longitudinal no curso. Estas ações acontecem no $4^{\circ}$ semestre e são focadas no desenvolvimento de técnicas de investigação clínica em um ambiente simulado. A motivação para tal construção de um modelo de ausculta cardíaca, surgiu diante da percepção das dificuldades apresentadas pelos alunos que descrevem como sendo um estudo com certo grau de dificuldade. Acredita-se que o exame físico cardiovascular, em especial a ausculta cardíaca, não deve ser direcionado apenas por métodos teóricos. É imprescindível simular sopros cardíacos, bem como o aparecimento de bulhas extras para que no futuro próximo não haja insegurança ao detectar um achado clínico alterado de um paciente. O processo então de aprendizagem deste modelo requer repetição e esforço, pois leva a proficiência, fazendo com que estes estudantes possam aprimorar suas habilidades.

Nessa proposta, a formação do conhecimento é mediada pelos professores que desafiam, provocam e incentivam estes universitários na construção do saber. Isso acontece porque a instituição de ensino tem investido na qualidade do discernimento prático, envolvendo o componente curricular em juízo, o que confere a excelência para a formação. Segundo Oliveira et al. (2013), os avanços tecnológicos nas últimas três décadas representam ferramentas úteis para compreensão da fisiopatologia e diagnóstico em diferentes áreas 
da Medicina, entretanto os instrumentos de tecnologia de informação e comunicação ainda são pouco utilizados com fins educacionais na graduação. No caso, a abordagem realizada entre professor/aluno/monitor da EBMSP contribui para o diferencial na educação médica ao trazer aspectos que envolvem a disseminação dos conteúdos, através de uma plataforma virtual de ensino.

Já de acordo com Kahwage Neto et al. (2017), em uma situação clínica, muitos alunos se sentem frustrados pela dificuldade de recordar conhecimentos adquiridos previamente e por se sentirem inaptos de aplicálos ao exame físico. Os docentes, por sua vez, ficam surpresos com os alunos, que parecem ter retido tão pouco. Pensando nisso, foram elaborados métodos práticos que envolvessem aspectos reais em um cenário simulado. Sendo assim, os estudantes de Medicina poderiam se habituar com os sons auscultatórios e por sua vez, a médio prazo, desempenharem um aumento substancial na acurácia de suas atividades. Assim, o objetivo é desenvolver e aplicar estratégia educacional para o ensino de ausculta cardíaca em estudantes do $4^{\circ}$ semestre, do curso de Medicina.

\section{Resumo do trabalho}

Para atender a demanda de estudo foi desenvolvida uma estação de treinamento clínico na plataforma Moodle, tendo como base a estratégia de entendimento do fenômeno acústico e repetição dos sons gravados. Associado a isso, para tornar o ensino mais fácil, procurou-se abordar com sapiência aspectos ligados a fisiopatologia. Os alunos presencialmente se acomodaram dentro de um ambiente de sala de aula, com uma estrutura tranquila e sem interferências do meio externo, para que não houvesse prejuízo na identificação do que estava sendo solicitado e, também, o meio propiciava a garantia do sinal da internet. A capacitação foi precedida por um pré-teste e ao término deste, foi aplicado um novo exame para verificar o reconhecimento dos sons cardíacos.

A monitoria é composta por doze monitores que foram divididos em dois grupos de seis pessoas e submetidos ao cumprimento do exercício, visando a revisão e aprimoramento da estação de ausculta. Foram utilizados fones padronizados e na sala os alunos estavam sendo supervisionados pelo docente e por um monitor responsável pelo seu grupo. Ao final, solicitou-se a realização de críticas e sugestões para o melhoramento da atividade. Desse modo, para o segundo grupo de monitores foi oferecido o treinamento já com as correções sugeridas pelo primeiro.

\section{Resumo dos resultados}

Tendo em vista a matriz curricular oferecida pela faculdade, o contato direto da semiologia médica se dá neste momento. Então, foi preciso haver adaptação para que as expectativas fossem atendidas e houvessem acessibilidade a todos, potencializando o grau de dificuldade processualmente. Sendo assim, foram excluídas situações de ausculta menos usual na prática clínica, dando enfoque nos achados semiológicos considerados de maior significado prognóstico e de caráter prevalente.

Houve adaptação da atividade para dinâmica dialogada em sala de aula, complementada pelo exercício realizado na plataforma Moodle, incluindo pré e pós-teste. Os alunos se sentiram satisfeitos e puderam com a vivência condicionar a audição, se familiarizando com os sons e vencendo obstáculos empregados devido a falta de percepção do que estava sendo auscultado. Isso Ihes conferem convicção e segurança dentro de uma abordagem realística.

\section{Conclusões}

Os autores consideram que a construção de um modelo para ensino de ausculta cardíaca é uma ferramenta que deve ser oferecida aos discentes, mas que seja disponibilizada em momentos diferentes do curso e com complexidade atenuante. Principalmente precedendo o contato com pacientes em outras situações, pois este processo de aprendizado, dentro de um cenário de simulação, contribui para uma melhor discussão e entendimento dos achados clínicos realísticos do cotidiano. 
Em vista disso, a repetição fundamentada e o amadurecimento são fundamentais para a incorporação e o desempenho de habilidades clínicas.

\section{Conflitos de interesses}

Nenhum conflito financeiro, legal ou político envolvendo terceiros (governo, empresas e fundações privadas, etc.) foi declarado para nenhum aspecto do trabalho submetido (incluindo mas não limitando-se a subvenções e financiamentos, participação em conselho consultivo, desenho de estudo, preparação de manuscrito, análise estatística, etc.).

\section{Referências}

1. Kahwage Neto SGK, Braga TKK, Portela MB, Andriolo RB. O Ensino de Habilidades Clínicas e a Aplicabilidade de um Guia Simplificado de Exame Físico na Graduação de Medicina. Rev Bras de Educ Méd. 2017;41(2):299-309. doi: 10.1590/1981-52712015v4 1n2RB20160110

2. Oliveira RJF, Silva AXG, Brígido ARD, Mafaldo RS, Paula VT, Diniz Junior J. Ferramentas de E-learning para melhoria do aprendizado em medicina. Revista Brasileira de Inovação Tecnológica em Saúde. 2013;3(3):55-61. doi: 10.18816/r-bits.v3i3.4484 
Rev. Inter. Educ. Saúde, Salvador, 2019 Outubro;3(1):45-52 Doi: 10.17267/2594-7907ijhe.v3i1.2296 | ISSN 2594-7907 
Rev. Inter. Educ. Saúde, Salvador, 2019 Outubro;3(1):45-52 Doi: 10.17267/2594-7907ijhe.v3i1.2296 | ISSN 2594-7907 
Rev. Inter. Educ. Saúde, Salvador, 2019 Outubro;3(1):45-52 Doi: 10.17267/2594-7907ijhe.v3i1.2296 | ISSN 2594-7907 
Rev. Inter. Educ. Saúde, Salvador, 2019 Outubro;3(1):45-52 Doi: 10.17267/2594-7907ijhe.v3i1.2296 | ISSN 2594-7907 
Rev. Inter. Educ. Saúde, Salvador, 2019 Outubro;3(1):45-52 Doi: 10.17267/2594-7907ijhe.v3i1.2296 | ISSN 2594-7907 